\title{
Coastal Communities and Climate Change: A Case Study in Gujarat, India
}

\section{Mini Review}

\section{Anil Kumar Roy* \\ CEPT University, India}

*Corresponding author: Anil Kumar Roy, CEPT University, Kasturbhai Lalbhai Campus, Navrangpura, Ahmedabad, Gujarat-380009, India

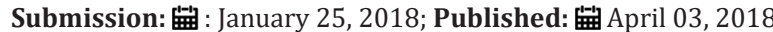

\section{Introduction}

Developing countries are highly vulnerable to climate change $[1,2]$. They have less coping capacity to deal with its negative impacts. India is one of the most vulnerable countries in South Asia. It urgently requires adaptation and mitigation measures to cope with possible impacts arising from extreme weather events

Climate Change Challenges In India due to climate change. Indian cities, particularly the coastal ones, are at a comparatively greater risk as their population is likely to grow rapidly and may reach 500 million over the next 50 years [3]. The assessment of climate change impacts and adaptability both at the macro region and micro levels is necessary to create effective mitigation policies $[4,5]$.

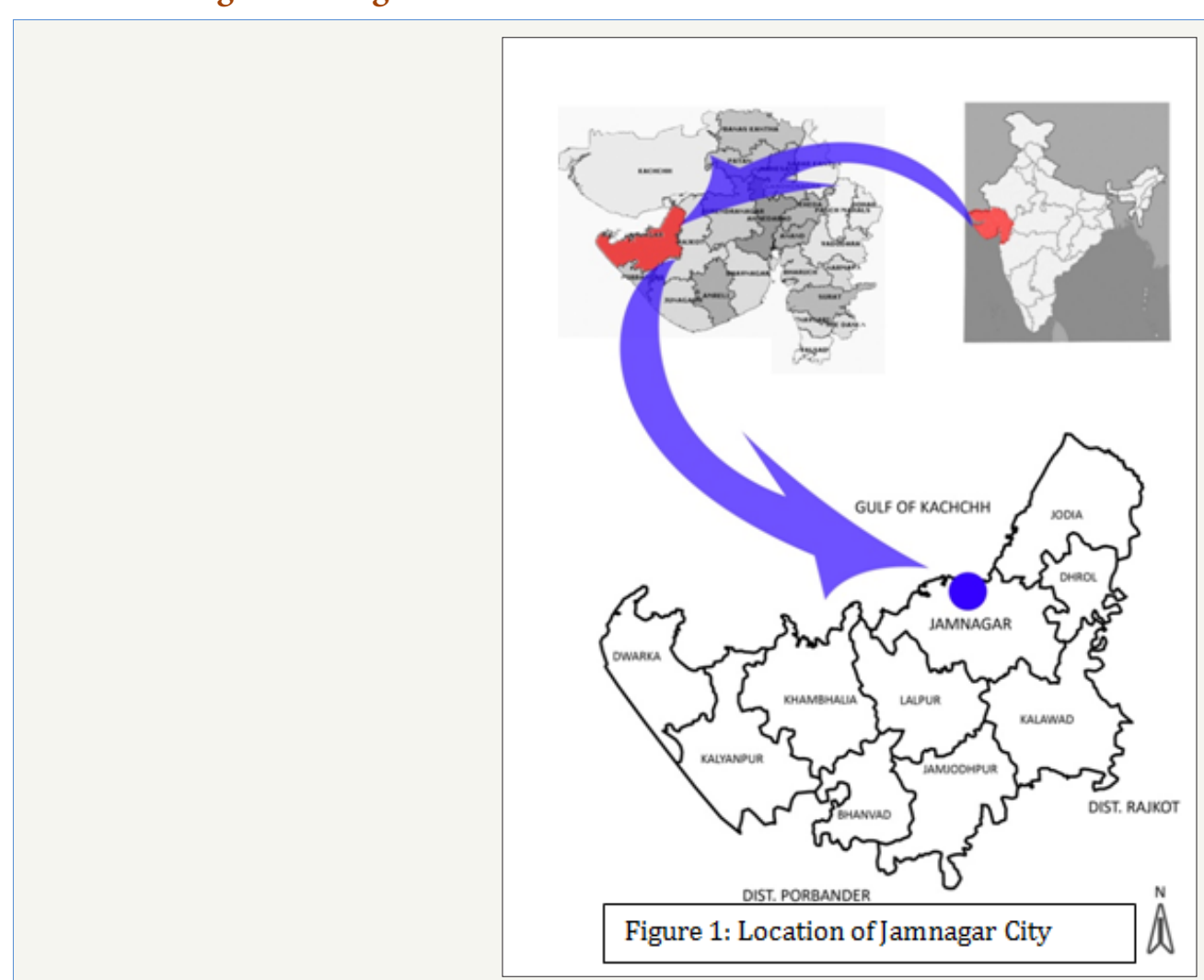

Figure 1: Location of Jamnagar city.

According to the India Disaster Knowledge Network, 12 percent of the total land mass of India is flood prone and 68 percent of the arable land is vulnerable to drought. The climate variability along India's coast and resultant sea-level rise will eventually have a tremendous socio-economic impact on local communities and their livelihood. Risks in Indian coastal cities are associated more with intrinsic vulnerability rather than external exposure to hazards. These areas are also experiencing rapid population growth and 
are likely to face greater climate change challenges. The case of Jamnagar City Region of Gujarat Coast in Gulf of Kutch, India shows the extent of vulnerability, exposure and perceptive challenges of climate change both at local level and at the household of coastal communities of farmers and fishermen Figure 1 for the location of Jamnagar City.

Jamnagar City Region-Perceptions and Preparedness for Climate Change

The analysis of climate variables reveals an increasing trend in the annual mean temperature observed for a period of 40 years during 1969 and 2009 in Jamnagar City-region (Figure 2). The average yearly rainfall does not confirm to the declining trends.
However, there has been a declining trend in the number of rainy days per year during the 50 years between 1955 and 2004 (Figure 3). This has resulted in the greater occurrence of droughts and floods in the region, leading to loss of life and property. Prime stakeholders of Jamnagar city face challenges such as scarcity of drinking water supply at sources, salinity ingress from the ocean, frequent flooding in the low lying areas (particularly slums) and high incidence of natural and manmade hazards. The stakeholders have these local priorities to tackle as far as urban planning is concerned, while national and state level climate change priorities are concerned with reduction of Green House Gases (GHGs) and preparation of new energy policy.

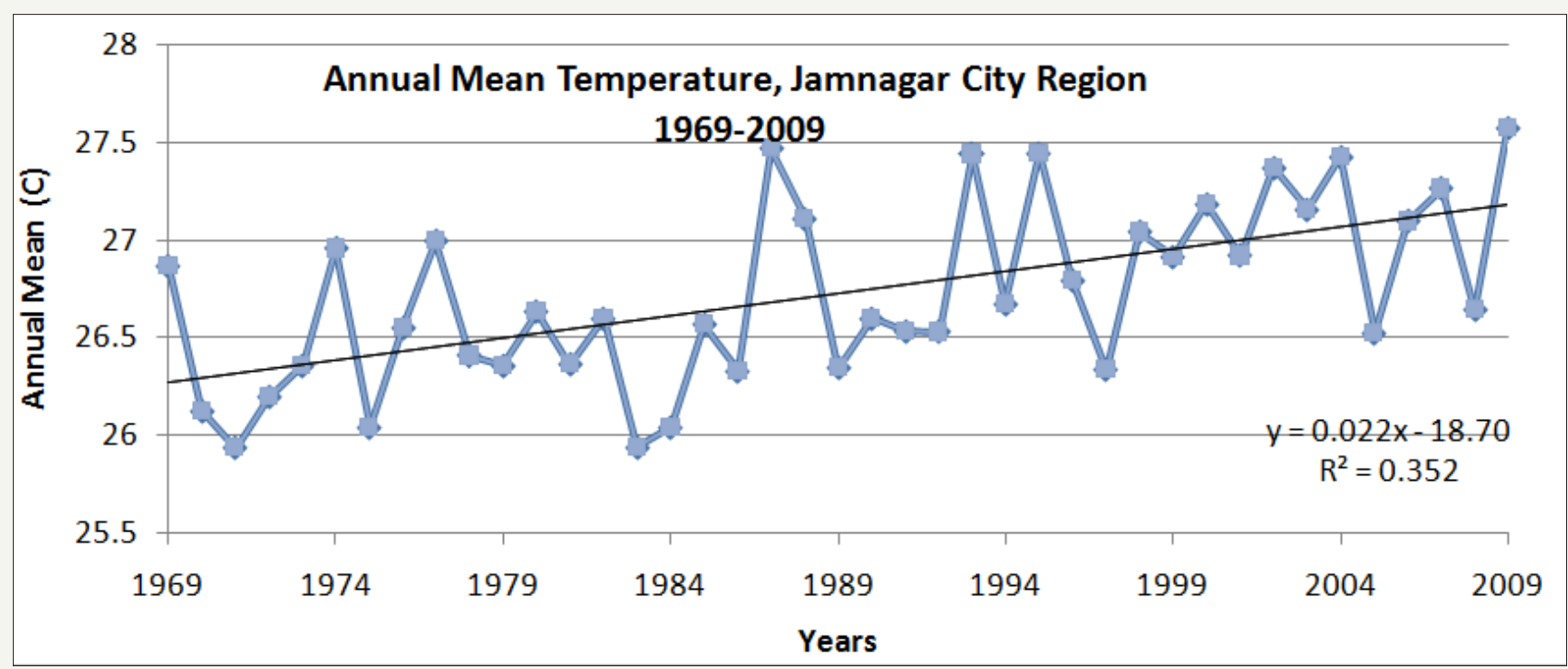

Figure 2: Annual mean temperature of Jamnagar city region- 1969-2009, Source: IMD, Pune for various years from 1969 to 2009.

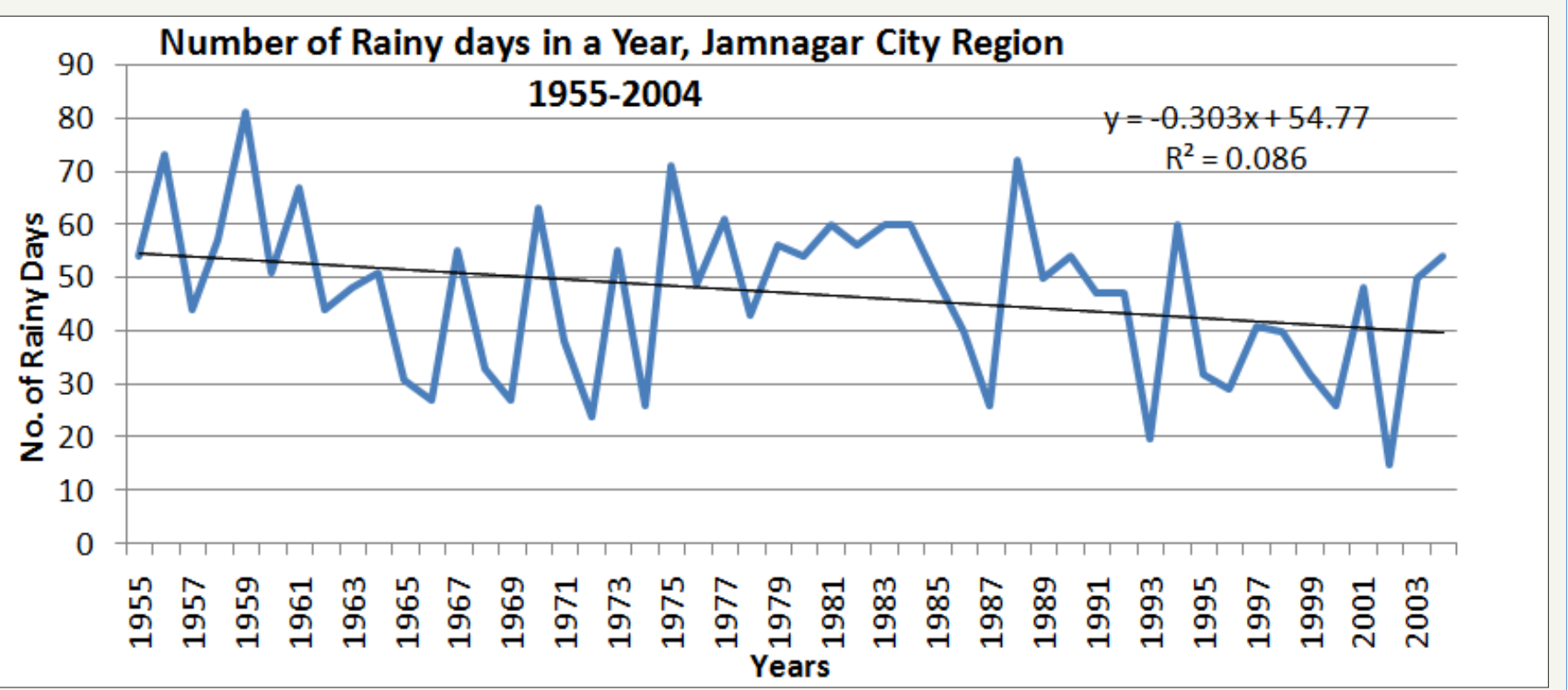

Figure 2: Number of rainy days in a year, Jamnagar city region-1955 to 2004, Source: IMD, Pune for various years from 1955 to 2004 . 


\section{Climate Change Challenges to Coastal Communities:} Perceived Vulnerability, Risk and Coping Mechanism

A survey of 100 households each from two coastal communities engaged in agriculture and fishing activities reveals that they are highly exposed to climate change impacts and are more sensitive towards extreme weather events such as droughts, floods, cyclones and salinity ingress. However, they have poor awareness of climate change impacts. They reported a change in their crop calendar due to the shifting nature of cropping season. This has resulted in reducing the desired yields of major crops. The fishing communities have reported decreasing tends in their fish catch throughout the year compared to a decade ago. The comparative assessment of the two communities shows that the fishing community is more vulnerable compared to agriculture community due to lack of awareness, the absence of social networks, use of low technology, lower socioeconomic status and greater dependency on coastal and marine resources for their livelihood.

\section{Conclusion}

Jamnagar city region, located in a coastal area, is vulnerable to climate change. The exposure and sensitivity to climate change variability of the city region have increased during the past 50 years. Climate variable in terms of rising temperature and reduction in a number of rainy days has resulted in greater exposure and sensitivity to climate change impacts. The adaptive capacity of the stakeholders is far from adequate, due to lack of awareness and general negligence regarding climate change. Community level vulnerability of those engaged in fishing and agricultural activities reveal higher exposure and sensitivity toward climate change variables, while their adaptive capacity is poor. It is evident that fishing community is comparatively more vulnerable to the climate change. The policy implications are clear. Local developmental priorities need to be considered while determining national and state level mitigation measures to mitigate climate change impacts. It works better when local communities are involved in climate change adaptation and mitigations measures. A study in Thailand shows that government policies are designed to mitigate climate change challenges faced by the farmers. However, it may take some time for the farmers to adapt to the new agriculture practices that combat climate change.

\section{References}

1. IFRC (2005) World disasters report, Geneva, Switzerland.

2. UNFCCC (2007) Climate Change: Impacts, vulnerabilities and adaptation in developing countries, United Nations Framework Convention on Climate Change (UNFCCC), p. 5.

3. Revi A (2008) Climate change risks: an adaptation and mitigation agenda for Indian cities, Environment \& Urbanization 20(1): 207-229.

4. Satterthwaite D, Saleemul H, Mark P, Hannah R, Patricia LR (2007) Adapting to climate change in urban areas; the possibilities and constraints in low-and middle-income nations. Human Settlements Working Paper Series, London.

5. (2006) Review of international federation of redcross and red crescent societies recovery operations, IFRC.
Creative Commons Attribution 4.0

International License

For possible submissions Click Here

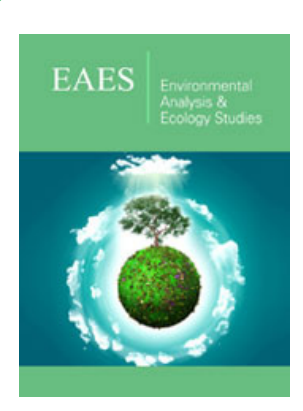

\section{Environmental Analysis \& Ecology Studies}

\section{Benefits of Publishing with us}

- High-level peer review and editorial services

- Freely accessible online immediately upon publication

- Authors retain the copyright to their work

- Licensing it under a Creative Commons license

- Visibility through different online platforms 